Purdue University Purdue e-Pubs

2019

\title{
Internet of Things in Smart Agriculture: Enabling Technologies
}

Abdul Salam

Purdue University, salama@purdue.edu

Syed Shah

Follow this and additional works at: https://docs.lib.purdue.edu/cit_articles

Part of the Computer and Systems Architecture Commons, Digital Communications and Networking Commons, Soil Science Commons, and the Systems and Communications Commons

Salam, Abdul and Shah, Syed, "Internet of Things in Smart Agriculture: Enabling Technologies" (2019). Faculty Publications. Paper 14. https://docs.lib.purdue.edu/cit_articles/14

This document has been made available through Purdue e-Pubs, a service of the Purdue University Libraries. Please contact epubs@purdue.edu for additional information. 


\section{Internet of Things in Smart Agriculture: Enabling Technologies}

\author{
Abdul Salam \\ Purdue University, USA \\ Email: salama@purdue.edu
}

\author{
Syed Shah \\ Prudential Financial, USA \\ Email: syed.shah@prudential.com
}

\begin{abstract}
In this paper, an IoT technology research and innovation roadmap for the field of precision agriculture (PA) is presented. Many recent practical trends and the challenges have been highlighted. Some important objectives for integrated technology research and education in precision agriculture are described. Effective IoT based communications and sensing approaches to mitigate challenges in the area of precision agriculture are presented.
\end{abstract}

\section{Precision Agriculture}

Precision agriculture [4], [20], [3], [8], [10], [12], [19], [20], [24], [36], [38], [35], [37], [32], [34], [26], [27], [28], [29], [25], [31], [33], [30], [41] [42], [43], [44], is the area in which technology can be used to effectively manage agriculture by understanding the temporal and spatial changes in soil, crop, production, and management through innovative techniques. The emerging Information Age will significantly affect the way we conduct and teach precision agriculture in universities and institutes of higher education. These impacts of change are already being felt across disciplines and across their missions of education, research, and outreach. The vital role of computing and information technologies in precision agriculture reflects far-reaching changes across our society - changes that are impacting virtually every human endeavor in the field of agriculture. Due to this, in precision agriculture, there are great opportunities for discovery and innovation. There are also many challenges in accelerating pace of change and broadening needs of water for food. The community need to organize and harness its resources to effectively and efficiently overcome these challenges. At all strategic levels, integrated education, research, and outreach measures are required that address precision agriculture community's need to acquire, manage, analyze, visualize, and utilize data and information to solve important cross-disciplinary problems and meet critical societal needs.

By 2020, Cisco's visual networking index [1] expects that 11.6 billion devices will be connected to the Internet. This number is greater than the projected population of the World (10 billion by 2050). The data insights from these devices will carry a $\$ 11$ trillion economic value. There is need of innovation in diverse set of precision agriculture areas. From an era where only tractors, seeders, combines, harvesters, and farm machinery were used with very limited technology, we are foreseeing a future in which computing and information technologies will be integral to every piece of equipment on the field. Growers will routinely use computers that are millions of times more powerful, connected to the Cloud with ubiquitous availability of data and information, and have communication capability through increasingly sophisticated interfaces. Many billions of data points are already being generated on daily basis at large agriculturally farms.

Virtually every agricultural area has been profoundly impacted by advances in computing technologies [2]. On the other hand, our academic pursuits of agricultural education and research have not adopted to it. Our current generation agrarian students will participate in the innovations of the next fifty years and witness changes that we can only imagine. Perhaps no arena of computing calls more upon our imagination than that of systems that match or exceed the abilities of human intelligence to utilize massive and rapidly growing data and information resources, apply advanced analytics to extract information and understand patterns, and arrive at intelligent solutions or actions in highly dynamic situations. These technologies are now the stuff of science fiction personified in androids and even the singularity of humans and machines, but they will dramatically reshape education, business, agriculture, health care, science, engineering, humanities, arts, entertainment, and other activities in ways that we cannot yet envision. In Fig. 1, the different components of the precision agriculture have been shown.

\section{Practical TRends And Challenges}

We highlight some recent practical trends and the challenges. Agricultural industry, governmental agencies, and growers have exceedingly critical needs for skills and innovations in computing and information technology. Accordingly, demand for computer and information technology education and university research has increased over decades and has exploded in recent years. The Bureau of Labor Statistics (BLS) in U.S Department of Labor forecasts a $12 \%$ increase in employment opportunities in the field of computer and information technology with new jobs being added through 2024 due to Internet of Things, Big Data Analytics, Cloud Computing and Cyber Security. Precision agriculture is also one of the major research drivers and a leader in quest for innovation. As a result, the emergence of new business models, services, and markets and technological advances will also contribute to substantial growth in GDP. Lack of training is one of the main challenges to adoption of precision agriculture. Other factors hindering the precision 


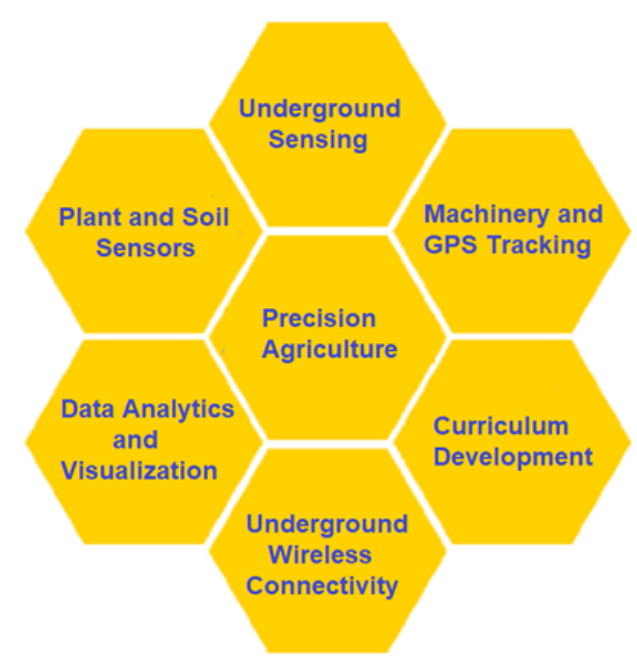

Fig. 1: The different components of the precision agriculture.

agriculture adoption are cost, return on investment, and lack of precision agriculture big data analytics [16].

\section{OBJeCTIVES}

In this section, we present some important objectives for integrated technology research and education in precision agriculture. The establishment of stakeholder engagement programs to understand how industry leaders perceive the adoption of precision agriculture technologies is needed. Their understanding and vision about technology adoption in precision agriculture will aid in eliminating of barriers to precision agriculture adoption. Another approach to engage farmers is by providing access to high speed internet connectivity. The reliable internet connectivity at affordable price will improve adoption of precision agricultural technology. Furthermore, it will benefit on-site data analysis of yield limiting factors. Through highspeed broadband connectivity to the cloud, the traffic demands of the novel precision agriculture applications can be met. Despite the high costs associated with deployment of rural broadband networks, the internet service providers can reap higher returns on investment helped by ubiquitous precision agriculture adoption in rural areas.

Our academic institutions must organize to more effectively perform the research driving innovations in precision agriculture to educate next generation students to use and creatively adapt both themselves and these new technologies for the future, and catalyze cross-fertilization of ideas and disciplines bridging education and research. Innovations in precision agriculture training are needed. The development and implantation of training programs will help to strengthen the technology expertise the researchers need to deal with precision agriculture big data analytics. As new products will span out in various farms, the decision making systems should be available to stakeholders at various levels, increasing impact and providing a problem driven environment for learning. The enhancement of undergraduate curriculum to include technology solutions and opportunities in precision agriculture is also a current need. Particularly, development of training materials to offer education and outreach to farmers will help in the areas of sustainable agricultural management systems, sustainable agriculture 1 production and management. The improved MS and $\mathrm{PhD}$ curriculum for precision agriculture will lead to growth in expertise in precision agriculture.

\section{EFFECTIVE APPROACHES}

One approach is that the diverse departments in universities can expand and develop education, research activities tailored to their disciplinary demands. By leveraging collaboration and utilizing core resources, on-going education and research efforts can achieve a level of success and scale that would not be possible with only the personnel and resources within their respective departments. This structured cross-disciplinary approach will also be more cost-effective in leveraging resources and avoiding duplication and so will most effectively surmount the challenges in the field. Particularly, centers to catalyze and support collaborative research, education precision agriculture computational analytics and informatics, Internet of Things (IoT) among participating units across the departments need to established.

Moreover, a signature constellation of undergraduate and graduate programs in precision agriculture computational analytics and informatics, rooted in participating department will play a vital role in sharing an innovative interdisciplinary core, and collaboration on visible, cross-disciplinary projects. Industry university cooperative research can be conducted by forming consortiums of industry and stakeholders across the country to leverage viable outcome.

Through the application of state-of-the-art approaches and technologies, and leveraging existing infrastructure, including advanced phenotyping and genetics, new techniques can be developed to maximize yield and nutrition while conserving water resources [18], [17]. Development of testbeds and platforms to implement and test new precision agriculture technologies for monitoring, planting, and harvesting through farmer/academia engagement will aid in technology adoption. These testbeds will also be useful in evaluation of in-field sensing, decision 
making, data science, and visual analytics solutions. Moreover, by targeted research development in controlling contamination of agricultural products during all stages of production and processing a new era can be created for a sustainable and healthy community. Pilot studies are also needed for innovations in storage and transport of grains, fruits, and vegetables to minimize loss caused by pests.

The agriculture is becoming exceedingly vulnerable to the soil degradation, water scarcity, deteriorating mountain ecosystems, and more variable and intense weather patterns (e.g., floods, drought, frosts). However, there are major gaps in our understanding of changes in agriculture and how these changes will effect agriculture. Improved knowledge needs to be acquired to anticipate, plan, and adapt to these changes and to gain new grounds in agriculture. Furthermore, efforts are needed to develop better detection techniques for per- and polyfluoroalkyl substances (PFAS), and PFAS-containing waste found in different soils. Among existing techniques, granular activated carbon (GAC) is a growing technology in PFAS treatment in water [23], [7]. However, there is a significant lack of data and procedure development in terms of fundamental understanding and quantification of medium properties. The adsorptive and destructive technologies, are considered for both soils and waters [9], [6]. Other remediation approaches are anion-exchange, ozofractionation, chemical oxidation, electrochemical oxidation, sonolysis, soils stabilization, and thermal technologies [5], [15], [21], [22]. These treatment technologies are not best suited to provide PFAS management systems with almost real-time sensing data to facilitate fast decision making [14], [13].

To meet the need of practical approaches to manage the potential environmental impacts of PFAS, environmental researchers must develop and implement new technologies to enhance detection and control of PFAS with fewer inputs. Enhanced techniques that are more practical and efficient in control, treatment, destruction, and removal of PFAS in soils are needed. This complex and arduous task requires interdisciplinary endeavors that combine various environmental science disciplines to develop such tools and implement them in the field to achieve this purpose.

The improved knowledge of different soil systems will contribute to the development of better underground sensing techniques. Lack of long term, large scale soil measurements is a major challenge as the existing models to predict different soil properties are developed using small scale testbeds and field measurements that also involves removal of soil from field locations for laboratory analysis. New technologies are needed to better understand the carbon and nitrogen cycle. To achieve this objective, the technology researchers and soil scientist have to play a dynamic role to develop advanced in-situ systems capable of measuring physical, chemical, and biological properties of soil in large scale fields containing different types of soil. In this regard, the recent advancements in the field of health and energy can be employed in precision agriculture.
Effective and reliable soil moisture sensing and irrigation management techniques also depend on advances in underground sensing and communication technology. Major challenges in these areas are manual installation and removal of soil moisture sensors during pre- and post-growing seasons and privacy concerns of the farmers about their fields. To overcome these precision agriculture adoption barriers, underground IoT with long term sensing capability coupled with wireless underground communications and networking are needed.

To build technology-aware, advanced precision agriculture practices, the innovation and automation in underground sensing and secure communications, data collection, analysis, and visualization will play a vital role [39], [40]. Sensors for soil and water quality across networked landscapes need to be developed. Moreover, integration of advances in precision agriculture data analytics, in-situ and remote sensing into working systems, indigenous and local information is required [10], [11]. The development and application of novel sensing and communication techniques for water resource conservation and enhancement of the crop yield is a major area in need of technology innovations. A large scale field IoT can be built using these wired and wireless technologies and sensing solutions. Creation of networked collection of existing soil type and moisture related databases will improve access to large scale consolidated data for decision making.

\section{CONCLUSIONS}

In conclusion, innovations and new knowledge are vital to enable a comprehensive and integrated technology approach to precision agriculture. Expertise across multiple domains including engineering and technology, agronomy, environmental sensing and monitoring, phonemics, soil fertility, entomology, data mining, machine learning and robotics are needed. All efforts should be made to connect expertise across these domains to examine important technology development and adoption challenges in precision agriculture. The application of the latest innovations in technology, sensing and communications will allow for substantial improvements in precision agriculture practices and management solutions.

\section{REFERENCES}

[1] "Cisco Visual Networking Index," https://www.cisco.com/c/en/us/ solutions/service-provider/visual-networking-index-vni/index.html.

[2] "Cornell Digital Agriculture," https://cuaes.cals.cornell.edu/ digital-agriculture.

[3] M. A. Akkaş, "Channel modeling of wireless sensor networks in oil," Wireless Personal Communications, pp. 1-19, 2017. [Online]. Available: http://dx.doi.org/10.1007/s11277-017-4083-9

[4] I. F. Akyildiz and E. P. Stuntebeck, "Wireless underground sensor networks: Research challenges," Ad Hoc Networks Journal, July 2006.

[5] B. M. Allred, J. R. Lang, M. A. Barlaz, and J. A. Field, "Orthogonal zirconium diol/c18 liquid chromatography-tandem mass spectrometry analysis of poly and perfluoroalkyl substances in landfill leachate," Journal of Chromatography A, vol. 1359, pp. 202-211, 2014.

[6] W. J. Backe, T. C. Day, and J. A. Field, "Zwitterionic, cationic, and anionic fluorinated chemicals in aqueous film forming foam formulations and groundwater from us military bases by nonaqueous large-volume injection hplc-ms/ms," Environmental science \& technology, vol. 47, no. 10 , pp. 5226-5234, 2013. 
[7] J. P. Benskin, B. Li, M. G. Ikonomou, J. R. Grace, and L. Y. Li, "Perand polyfluoroalkyl substances in landfill leachate: patterns, time trends, and sources," Environmental science \& technology, vol. 46, no. 21, pp. $11532-11540,2012$.

[8] H. R. Bogena, M. Herbst, J. A. Huisman, U. Rosenbaum, A. Weuthen, and $\mathrm{H}$. Vereecken, "Potential of wireless sensor networks for measuring soil water content variability," Vadose Zone Journal, Nov. 2010.

[9] R. C. Buck, J. Franklin, U. Berger, J. M. Conder, I. T. Cousins, P. De Voogt, A. A. Jensen, K. Kannan, S. A. Mabury, and S. P. van Leeuwen, "Perfluoroalkyl and polyfluoroalkyl substances in the environment: terminology, classification, and origins," Integrated environmental assessment and management, vol. 7, no. 4, pp. 513-541, 2011.

[10] X. Dong, M. C. Vuran, and S. Irmak, "Autonomous precision agricultrue through integration of wireless underground sensor networks with center pivot irrigation systems," Ad Hoc Networks (Elsevier), 2012.

[11] A. Farid, A. Alshawabkeh, and C. Rappaport, "Electromagnetic waves in contaminated soils," Book chapter published in Electromagnetic Waves Propagation in Complex Matter, Ahmed Kishk, ed., pp. 117-154, Jul. 2011.

[12] H. Guo and Z. Sun, "Channel and energy modeling for self-contained wireless sensor networks in oil reservoirs," IEEE Trans. Wireless Communications, vol. 13, no. 4, pp. 2258-2269, April 2014.

[13] H. Hamid, L. Y. Li, and J. R. Grace, "Review of the fate and transformation of per-and polyfluoroalkyl substances (pfass) in landfills," Environmental Pollution, vol. 235, pp. 74-84, 2018.

[14] X. C. Hu, D. Q. Andrews, A. B. Lindstrom, T. A. Bruton, L. A. Schaider, P. Grandjean, R. Lohmann, C. C. Carignan, A. Blum, S. A. Balan et al., "Detection of poly-and perfluoroalkyl substances (pfass) in us drinking water linked to industrial sites, military fire training areas, and wastewater treatment plants," Environmental science \& technology letters, vol. 3, no. 10 , pp. $344-350,2016$

[15] C. A. Huset, M. A. Barlaz, D. F. Barofsky, and J. A. Field, "Quantitative determination of fluorochemicals in municipal landfill leachates," Chemosphere, vol. 82, no. 10, pp. 1380-1386, 2011.

[16] S. Irmak, "Inter-annual variation in long-term center pivot-irrigated maize evapotranspiration and various water productivity response indices: Part I: Grain yield, actual and basal evapotranspiration, irrigation-yield production functions, evapotranspiration-yield production functions, and yield response factors," Journal of Irrigation and Drainage Engineering, vol. 141, no. 5, p. 04014068, May 2015.

[17] S. Irmak and et.al., "Large scale on-farm implementation of soil moisturebased irrigation management strategies for increasing maize water productivity," Transactions of the ASABE, vol. 55, no. 3, pp. 881-894, 2012.

[18] S. Irmak and W. R. Rathje, "Plant growth and yield as affected by wet soil conditions due to flooding or over-irrigation," University of NebraskaLincoln Extension NebGuide, Tech. Rep. G1904, 2008.

[19] A. Konda, A. Rau, M. A. Stoller, J. M. Taylor, A. Salam, G. A. Pribil, C. Argyropoulos, and S. A. Morin, "Soft microreactors for the deposition of conductive metallic traces on planar, embossed, and curved surfaces," Advanced Functional Materials, vol. 28, no. 40, p. 1803020.

[20] A. Markham and N. Trigoni, "Magneto-inductive networked rescue system (miners): Taking sensor networks underground," in Proceedings of the 11th ICPS, ser. IPSN '12. ACM, 2012, pp. 317-328.

[21] N. Merino, Y. Qu, R. A. Deeb, E. L. Hawley, M. R. Hoffmann, and S. Mahendra, "Degradation and removal methods for perfluoroalkyl and polyfluoroalkyl substances in water," Environmental Engineering Science, vol. 33, no. 9, pp. 615-649, 2016.

[22] M. F. Rahman, S. Peldszus, and W. B. Anderson, "Behaviour and fate of perfluoroalkyl and polyfluoroalkyl substances (pfass) in drinking water treatment: a review," Water research, vol. 50, pp. 318-340, 2014.

[23] I. Ross, J. McDonough, J. Miles, P. Storch, P. Thelakkat Kochunarayanan, E. Kalve, J. Hurst, S. S. Dasgupta, and J. Burdick, "A review of emerging technologies for remediation of pfass," Remediation Journal, vol. 28, no. 2, pp. 101-126, 2018.

[24] N. Saeed, T. Y. Al-Naffouri, and M.-S. Alouini, "Towards the internet of underground things: A systematic survey," arXiv preprint arXiv:1902.03844, 2019.

[25] A. Salam, "Pulses in the sand: Long range and high data rate communication techniques for next generation wireless underground networks," ETD collection for University of Nebraska - Lincoln, no. AAI10826112, 2018. [Online]. Available: http://digitalcommons.unl.edu/ dissertations/AAI10826112
[26] A. Salam, "A comparison of path loss variations in soil using planar and dipole antennas," in 2019 IEEE International Symposium on Antennas and Propagation. IEEE, Jul 2019.

[27] A. Salam, "A path loss model for through the soil wireless communications in digital agriculture," in 2019 IEEE International Symposium on Antennas and Propagation. IEEE, Jul 2019.

[28] A. Salam, "Underground environment aware MIMO design using transmit and receive beamforming in internet of underground things," in 2019 International Conference on Internet of Things (ICIOT 2019), San Diego, USA, Jun. 2019.

[29] A. Salam, "An underground radio wave propagation prediction model for digital agriculture," Information, vol. 10, no. 4, 2019. [Online]. Available: http://www.mdpi.com/2078-2489/10/4/147

[30] A. Salam, "Underground soil sensing using subsurface radio wave propagation," in 5th Global Workshop on Proximal Soil Sensing, Columbia, MO, May 2019.

[31] A. Salam and S. Shah, "Urban underground infrastructure monitoring IoT: the path loss analysis," in 2019 IEEE 5th World Forum on Internet of Things (WF-IoT) (WF-IoT 2019), Limerick, Ireland, Apr. 2019.

[32] A. Salam and M. C. Vuran, "EM-Based Wireless Underground Sensor Networks," in Underground Sensing, S. Pamukcu and L. Cheng, Eds. Academic Press, 2018, pp. $247-285$.

[33] A. Salam, M. C. Vuran, X. Dong, C. Argyropoulos, and S. Irmak, "A theoretical model of underground dipole antennas for communications in internet of underground things," IEEE Transactions on Antennas and Propagation, 2019.

[34] A. Salam, M. C. Vuran, and S. Irmak, "Di-sense: In situ realtime permittivity estimation and soil moisture sensing using wireless underground communications," Computer Networks, vol. 151, pp. 31 - 41, 2019. [Online]. Available: http://www.sciencedirect.com/science/ article/pii/S1389128618303141

[35] A. Salam and M. C. Vuran, "Smart underground antenna arrays: A soil moisture adaptive beamforming approach," in Proc. 36th IEEE INFOCOM 2017, Atlanta, USA, May 2017.

[36] A. Salam and M. C. Vuran, "Wireless underground channel diversity reception with multiple antennas for internet of underground things," in Proc. IEEE ICC 2017, Paris, France, May 2017.

[37] A. Salam, M. C. Vuran, and S. Irmak, "Pulses in the sand: Impulse response analysis of wireless underground channel," in Proc. IEEE INFOCOM 2016, San Francisco, USA, Apr. 2016.

[38] A. Salam, M. C. Vuran, and S. Irmak, "Towards internet of underground things in smart lighting: A statistical model of wireless underground channel," in Proc. 14th IEEE International Conference on Networking, Sensing and Control (IEEE ICNSC), Calabria, Italy, May 2017.

[39] A. R. Silva and M. C. Vuran, " $C P S^{2}$ : Integration of center pivot systems with wireless underground sensor networks for autonomous precision agriculture," in to appear in Proc. ACM/IEEE First International Conference on Cyber-Physical Systems (ICCPS' 10), Stockholm, Sweden, April 2010.

[40] A. R. Silva and M. C. Vuran, "Development of a Testbed for Wireless Underground Sensor Networks," EURASIP Journal on Wireless Communications and Networking, vol. 2010, 2010.

[41] S. Temel, M. C. Vuran, M. M. Lunar, Z. Zhao, A. Salam, R. K. Faller, and C. Stolle, "Vehicle-to-barrier communication during real-world vehicle crash tests," Computer Communications, vol. 127, pp. 172 - 186 2018. [Online]. Available: http://www.sciencedirect.com/science/article/ pii/S0140366417305224

[42] M. J. Tiusanen, "Soil scouts: Description and performance of single hop wireless underground sensor nodes," Ad Hoc Networks, vol. 11, no. 5, pp. $1610-1618,2013$.

[43] M. C. Vuran, A. Salam, R. Wong, and S. Irmak, "Internet of underground things in precision agriculture: Architecture and technology aspects," Ad Hoc Networks, 2018. [Online]. Available: http://www.sciencedirect.com/science/article/pii/S1570870518305067

[44] M. C. Vuran, A. Salam, R. Wong, and S. Irmak, "Internet of underground things: Sensing and communications on the field for precision agriculture," in 2018 IEEE 4th World Forum on Internet of Things (WF-IoT) (WF-IoT 2018), , Singapore, Feb. 2018. 